\title{
Sympathoadrenal and cardiovascular responses to mental stress, isometric handgrip, and cold pressor test in asymptomatic young men with primary $\mathrm{T}$ wave abnormalities in the electrocardiogram ${ }^{\star}$
}

\author{
JAN-HENRIK ATTERHÖG, KEITH ELIASSON, PAUL HJEMDAHL
}

From the Departments of Clinical Physiology and Internal Medicine, Karolinska Hospital, and the Department of Pharmacology, Karolinska Institutet, Stockholm, Sweden

SUMMARY Sympathoadrenal activity was evaluated by the determination of plasma catecholamines at rest and during stressful provocations in 12 young asymptomatic men with primary $T$ wave abnormalities in the electrocardiogram and without a history or signs of cardiac disease (group $\mathrm{T}$ ) and in 13 matched controls. The $T$ wave abnormalities consisted of notching, flattening, or inversion without concomitant ST depression in leads II, V4, and V6. At rest, plasma noradrenaline was approximately twice as high in group $\mathrm{T}$ as in the controls, whereas plasma adrenaline and dopamine levels were similar in the two groups. Non-invasive haemodynamic monitoring (blood pressure and impedance cardiography) showed a significantly higher systolic blood pressure and impedance signs of increased cardiac contractility without tachycardia in group T. A standardised mental stress test, isometric hand grip, and a cold pressor test all significantly increased blood pressure, as well as noradrenaline and adrenaline in both groups. The increases in diastolic blood pressure and adrenaline tended to be larger in group $T$ in connection with stressful provocations, indicating increased sympathoadrenal reactivity. The increases in systolic blood pressure and noradrenaline persisted during provocations. In both groups the cold pressor test, which raises blood pressure mainly by vasoconstriction, increased noradrenaline more than did the other two tests, which are believed to act mainly by cardiac stimulation. Because of the low adrenaline levels found, neurogenic mechanisms appear to be of greater importance than adrenaline for the circulatory responses to each of these provocations. The study provides evidence in favour of increased sympathetic activity at rest and enhanced sympathoadrenal reactivity during stress in subjects with primary $\mathrm{T}$ wave abnormalities. These electrocardiographic findings may therefore be explained by increased sympathoadrenal activity.

Emotional and other stimuli causing sympathetic activity may produce changes in the electrocardiogram. ${ }^{12}$ For example, beta-adrenergic blockade may reverse ST-T changes resembling myocardial ischaemia in asymptomatic patients without other signs of organic heart disease. ${ }^{34}$ Similarly, patients with the so-called "primary hyperkinetic heart syndrome" show $\mathrm{T}$ wave alterations (flattening, inversion) which are accentuated by tilting, mental stress, or isoprenaline, and are counteracted by beta-adrenoreceptor blockade or cold. ${ }^{5}$

\footnotetext{
^ Supported by grants from Karolinska Institutet, Åke Wibergs foundation, Jeanssons foundation, Tore Nilssons fund, and Groschinsky's fund. Received for publication 6 March 1981
}

The present study is concerned with the aetiology of $T$ wave abnormalities in the electrocardiograms of a group of asymptomatic young men in whom they were found at routine examination for induction to military service. These men (group $\mathrm{T}$ ) have been compared with a randomly selected age-matched group of healthy men with normal electrocardiograms (group C). To elucidate the importance of sympathoadrenal activity in causing these $T$ wave changes plasma catecholamines, haemodynamics (with noninvasive techniques), and electrocardiograms at rest and in connection with mental stress, isometric exercise, a cold pressor test, and the administration of atropine were studied. Results obtained in connection with dynamic exercise as well as a detailed description 
of the electrocardiographic and vectorcardiographic data from the present study are presented elsewhere. ${ }^{6}$

The aims of the investigation were threefold: to determine in group $\mathrm{T}$ first, if indices of sympathoadrenal function such as plasma noradrenaline and adrenaline were changed; second, whether the electrocardiographic abnormalities were associated with haemodynamic alterations at rest or during the various provocations, and third, if the group showed altered reactivity with regard to haemodynamic variables and/or sympathoadrenal function in connection with stressful stimuli.

\section{Subjects}

These were 12 men aged 18 to 19 years with primary $\mathrm{T}$ wave abnormalities but without other evidence of heart disease (group T). The $\mathrm{T}$ wave abnormalities consisted of either a notch in the $\mathrm{T}$ wave making it partly or totally negative, a low amplitude $T$ wave without ST depression, or a break in the progression of $\mathrm{T}$ wave amplitude from V1 to V6 (unpublished

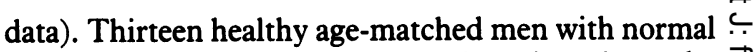
electrocardiograms were randomly selected at the $\overrightarrow{\vec{D}}$ military induction entre and participated in this investigation after informed consent to constitute a control group (group $\mathrm{C}$ ). The subjects in group $\mathrm{T}$ were somewhat shorter $(177 \cdot 8 \pm 6.7$ vs $184 \cdot 0 \pm 4.6 \mathrm{~cm}$; $\mathrm{p}<0.05)$ and lighter $(69.4 \pm 5.6$ vs $76.5 \pm 11.9 \mathrm{~kg}$; $\mathrm{p}<0 \cdot 10)$ than their controls.

\section{Procedure and methods}

The study was approved by the Ethical Committee at Karolinska Hospital. The experimental procedure started at 11.30 am with a lunch that was identical for all subjects, who had been told not to smoke or to consume alcohol, tea, coffee, chocolate, or bananas on the day of the experiment. The study included a $\frac{\mathrm{O}}{3}$ standardised mental stress test, a sustained isometric hand grip test, a cold pressor test, and the administration of atropine. Measurements at rest and in connection with each of these provocations included impedance cardiography, Frank vectorcardiography, blood

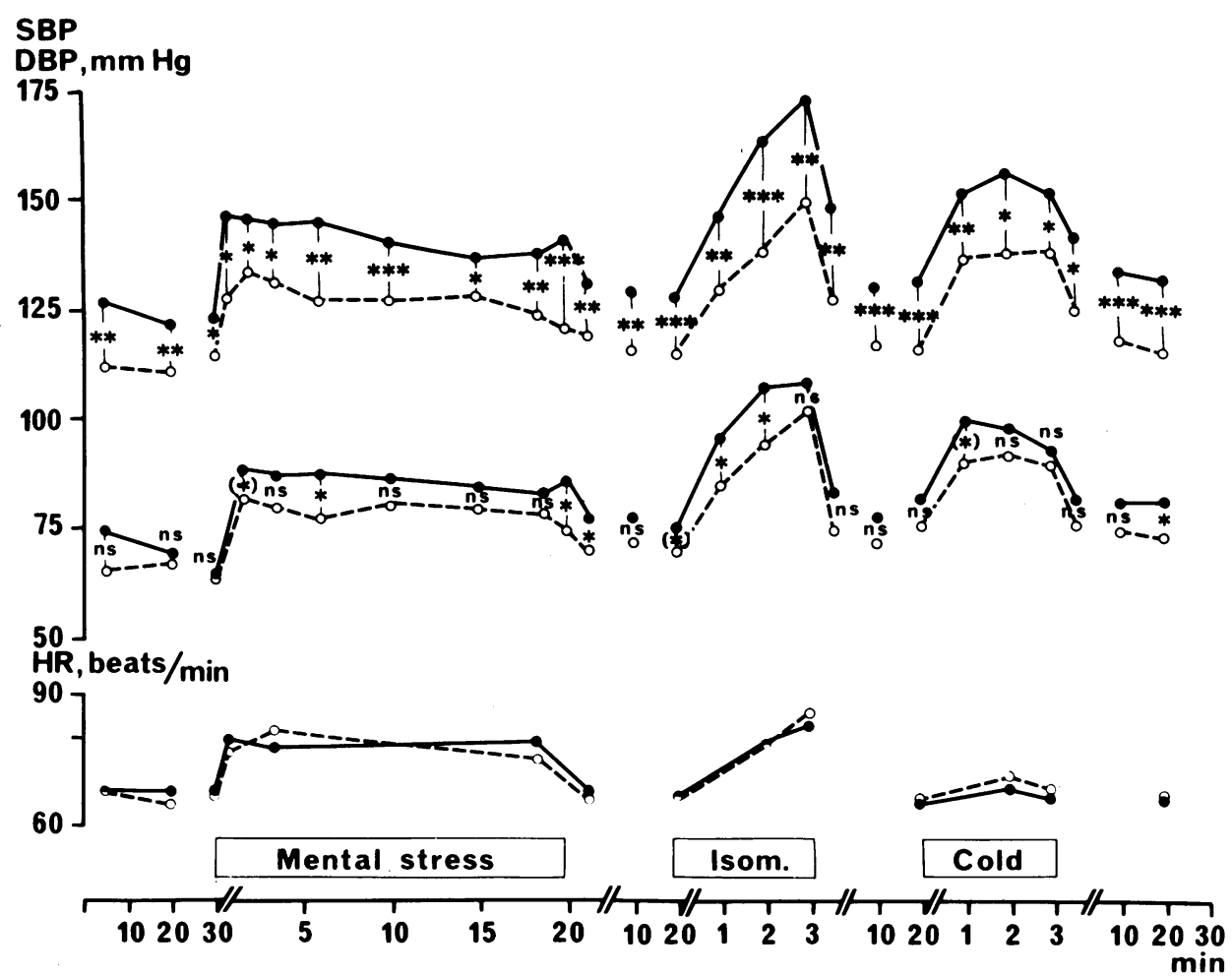

Fig. 1 Systolic and diastolic blood pressures $(S B P, D B P)$ and heart rates $(H R)$ in subjects with $T$ wave abnormalities (group $T$, continuous lines) and normal electrocardiograms group $C$, interrupted lines) in connection with mental stress, isometric hand grip, and cold pressor test. Significance of differences between groups is given for each determination. For information regarding the significance of effects induced by either provocation and differences between group responses see Table 1 and 2. 
pressure, and plasma catecholamine determinations. The order of the tests and the time schedule are illustrated in Fig. 1 and 2. The subjects were seated throughout.

The mental stress consisted of exposure to Stroop's colour word conflict test in a modified film version lasting 20 minutes. ${ }^{7}$ Immediately before and after the test the subjects ranked their mean experience of "stress" in daily living and in the test situation by a graphic self rating scale. ${ }^{8}$ The sustained isometric hand grip test was performed with the right hand on a strain gauge dynamometer with immovable handles for three minutes at one-third of the maximal voluntary power determined beforehand. The force developed was shown to the subject on an oscilloscope. The cold pressor test consisted of the immersion of the right hand in ice water (that is 1.5 to $2^{\circ} \mathrm{C}$ ) to a level $5 \mathrm{~cm}$ above the wrist for three minutes. An attempt to evaluate the vagal tone was made by determining the heart rate response to a slow intravenous injection of atropine $(1 \mathrm{mg}$ to subjects weighing less than $65 \mathrm{~kg}, 1 . \hat{z} 5 \mathrm{mg}$ between 65 and 75 $\mathrm{kg}$, and $1.5 \mathrm{mg}$ to those weighing more than $75 \mathrm{~kg}$ ) at the end of the experiment. A 30 minute rest period in the seated position preceded the mental stress test, and 20 minute rest periods were allowed before each of the subsequent provocations.

Blood pressure was recorded by a semiautomated apparatus sensing the Korotkoff sounds with a microphone built into a conventional blood pressure cuff placed on the left upper arm. The apparatus, which was constructed at our laboratory, was tested regularly and was found to give correct recordings of blood pressure without baseline drift. Furthermore, readings have been validated against intra-arterial blood pressure determinations and a good agreement has been found under the circumstances prevailing in this study. The blood pressure was measured every five minutes at rest and every minute for five minutes before and during each test.

Blood samples $(10 \mathrm{ml})$ for the determination of plasma noradrenaline, adrenaline, and dopamine were drawn from an indwelling venous catheter inserted into a median cubital vein of the left arm and with the tip positioned above the blood pressure cuff. The blood was collected in plastic centrifuge tubes containing EDTA (10 nmol final concentration) which were immediately cooled in ice water. After centrifugation at $4^{\circ} \mathrm{C}$ the plasma was frozen at $-80^{\circ} \mathrm{C}$ for later determination of catecholamines by high

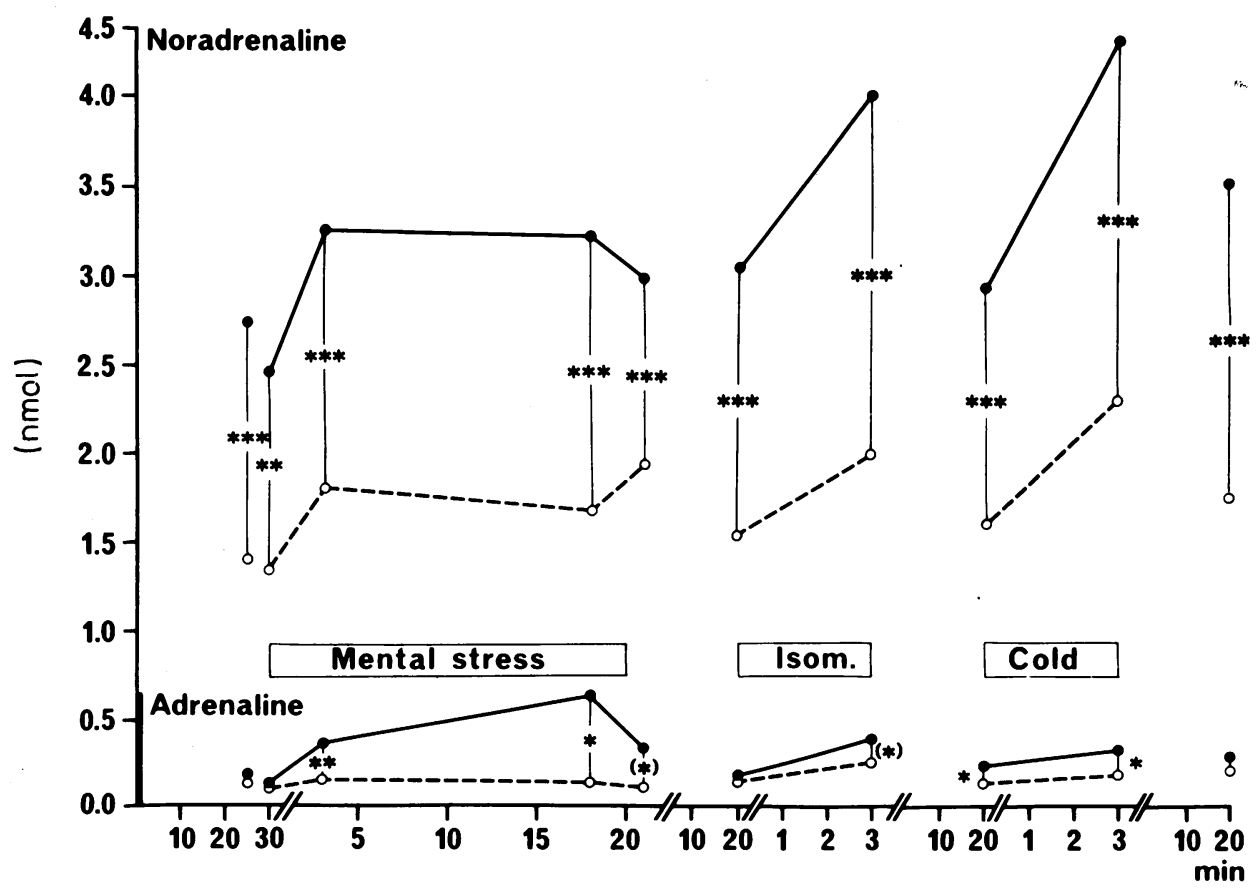

Fig. 2 Plasma adrenaline and noradrenaline concentrations in subjects with $T$ wave abnormalities (group $T$, continuous lines) and normal electrocardiograms (group $C$, interrupted lines) in connection with mental stress, isometric hand grip, and cold pressor test. Significance of differences between groups is given for each determination. For information regarding the significance of effects induced by either provocation and differences between group responses see Tables 1 and 2 . 
performance liquid chromatography. This method has been validated against radioenzymatic methods. ${ }^{9}$ When assayed on different cation exchange columns ( 25 to $30 \mathrm{~cm}$ by 4 to $4.6 \mathrm{~mm}$ stainless steel columns packed with Nucleosil 10SA, Macherey-Nagel Co.) an interassay coefficient of variation for determinations of plasma noradrenaline of $2.4 \%$ (in the normal nanomolar concentration range) and for adrenaline of $13.4 \%$ (at basal levels of 0.1 to $0.2 \mathrm{nmol}$; less at higher levels) was obtained. Intra-assay coefficients of variation $1 \cdot 8 \pm 0 \cdot 3 \%$ for noradrenaline and $15 \cdot 1 \pm 1 \cdot 9 \%$ for adrenaline in the above-mentioned concentration ranges have been obtained (mean values \pm SEM from nine assays on three different columns). The time schedule for plasma catecholamine sampling is given in Fig. 2.

Impedance cardiography was performed with an IFM Minnesota impedance cardiograph model $304 \mathrm{~A}$ as described by Gabriel et al. ${ }^{10}$ The phonocardiogram was obtained with a piezoelectric microphone. The first derivative thoracic impedance $(\mathrm{dZ} / \mathrm{dt})$ signal was recorded both unfiltered and low-pass filtered at 25 $\mathrm{Hz}$ with a filter slope of $24 \mathrm{~dB}$ per octave (Krohn-Hite 7750) on an ink-jet multichannel graphic recorder (Mingograph 61, Siemens-Elema). In each measurement the average of 10 beats was used for calculation.
Estimates of stroke volumes and consequently cardiac outputs showed large inter- and intra-individual of variations which sometimes gave results far from the physiological range. These disturbances were mainly caused by baseline shifts resulting from the inability of the subjects to remain still. The following variables were more independent of the varying distance \& between the electrode tapes and thus gave reliable $\vec{\circ}$ estimates: heart rate, pre-ejection period (PEP), left ventricular ejection time (LVET), Zo (the mean thoracic impedance), $\mathrm{dZ} / \mathrm{dt} \operatorname{maximum} \times(\mathrm{R}-\mathrm{Z})^{-1}$ index (where $\mathrm{Z}$ is the maximum deflection of the $\mathrm{dZ} / \mathrm{dt}$ curve and $\mathrm{R}$ is the maximum positive deflection $\vec{\circ}$ in lead $x$ in a vectorcardiographic recording). PEP $\omega$ and LVET were corrected for differences in heart rate (PEPc, LVETc) according to the regression equations of Weissler et al. ${ }^{11}$

The difference between group means was tested for significance using Student's t test, with the exception of the plasma catecholamine results where the nonparametric Mann-Whitney U test was used. Courses of events were tested by $t$ test for paired observations and Wilcoxon $U$ test for paired groups. The relation $\overrightarrow{0}$ between two variables was studied with linear $\propto$ regression analysis or sign test on slopes of covariation.

Table 1 Heart rate $(H R)$, blood pressures $(S B P, D B P)$, and plasma catecholamines before, during, and after mental stress test in subjects with $T$ wave abnormalities (group $T$ ) and normal electrocardiograms (group $C$ )

\begin{tabular}{|c|c|c|c|c|c|c|c|c|c|c|c|}
\hline & \multicolumn{2}{|l|}{ At rest } & \multicolumn{2}{|c|}{$\begin{array}{l}3 \text { min mental } \\
\text { stress }\end{array}$} & \multirow{2}{*}{$\begin{array}{l}\text { Signif. } \\
\text { of diff. } \\
2 / p<\end{array}$} & \multicolumn{2}{|c|}{$\begin{array}{l}18 \text { min mental } \\
\text { stress }\end{array}$} & \multirow{2}{*}{$\begin{array}{l}\text { Signif. } \\
\text { of diff. } \\
2 / p<\end{array}$} & \multicolumn{2}{|c|}{$\begin{array}{l}4 \text { min after } \\
\text { mental stress }\end{array}$} & \multirow{2}{*}{$\begin{array}{l}\text { Signif. } \\
\text { of diff. } \\
2 / p<\end{array}$} \\
\hline & $\bar{X}$ & $S D$ & $\bar{X}$ & $S D$ & & $\bar{X}$ & $S D$ & & $\bar{X}$ & $S D$ & \\
\hline \multicolumn{12}{|l|}{ Heart rate (beats $/ \mathrm{min})$} \\
\hline Group $T$ & 68 & 9 & 78 & 11 & 0.01 & 80 & 10 & 0.001 & 69 & 8 & - \\
\hline Group C & 67 & 13 & 82 & 16 & 0.001 & 76 & 14 & 0.001 & 67 & 11 & - \\
\hline Signif. of diff. $1 / \mathrm{p}<$ & & - & & - & -3 & & & -3 & & - & -3 \\
\hline \multicolumn{12}{|c|}{ Systolic blood pressure $(\mathrm{mmHg})$} \\
\hline Group $T$ & 125 & 10 & 143 & 7 & 0.001 & 137 & 11 & 0.001 & 133 & 9 & 0.001 \\
\hline Group C & 112 & 9 & 131 & 13 & 0.001 & 125 & 10 & 0.001 & 120 & 9 & 0.001 \\
\hline Signif. of diff. $1 / \mathrm{p}<$ & & 0.001 & & 0.05 & -3 & & 01 & -3 & & 0.01 & -3 \\
\hline \multicolumn{12}{|c|}{ Diastolic blood pressure $(\mathrm{mmHg})$} \\
\hline Group T & 70 & 7 & 88 & 15 & 0.001 & 84 & 11 & 0.001 & 80 & 12 & 0.001 \\
\hline Group C & 67 & 7 & 80 & 7 & 0.001 & 76 & 7 & 0.001 & 73 & 7 & 0.01 \\
\hline Signif. of diff. $1 / \mathrm{p}<$ & & - & & - & -3 & & 10 & $0.05^{3}$ & & $0 \cdot 10$ & $0.05^{3}$ \\
\hline \multicolumn{12}{|l|}{ Adrenaline (nmol) } \\
\hline Group $T$ & $0 \cdot 17$ & $(0 \cdot 15)$ & 0.36 & $(0 \cdot 18)$ & 0.01 & 0.63 & $(0.93)$ & 0.01 & 0.34 & $(0.57)$ & - \\
\hline Group C & $0 \cdot 14$ & $(0.07)$ & $0 \cdot 20$ & $(0 \cdot 10)$ & 0.01 & $0 \cdot 16$ & $(0 \cdot 13)$ & - & $0 \cdot 11$ & $(0 \cdot 10)$ & $0 \cdot 10$ \\
\hline Signif. of diff. $1 / \mathrm{p}<$ & & - & & 0.01 & $0 \cdot 10^{3}$ & & 05 & $0.05^{3}$ & & $0 \cdot 10$ & -3 \\
\hline \multicolumn{12}{|l|}{ Noradrenaline (nmol) } \\
\hline Group T & $2 \cdot 65$ & $(1 \cdot 04)$ & $3 \cdot 25$ & $(1 \cdot 28)$ & - & $3 \cdot 23$ & $(0 \cdot 71)$ & 0.05 & 2.98 & $(0 \cdot 76)$ & $0 \cdot 10$ \\
\hline Group C & 1.47 & $(0.47)$ & $1 \cdot 81$ & $\quad(0.80)$ & 0.05 & $1 \cdot 70$ & $(0.48)$ & 0.001 & 1.94 & $(0.52)$ & 0.001 \\
\hline Signif. of diff. $1 / p<$ & & 0.001 & & 0.001 & -3 & & 001 & $0.05^{3}$ & & 0.001 & -3 \\
\hline
\end{tabular}

Significance of differences is given between the groups at corresponding determinations ( $1 /$ ), for responses induced by the test in each group ( $2 /$ ) and for the difference in increase of a variable between groups in connection with a test (3/). The catecholamine SDs are within brackets since plasma catecholamine concentrations had a skewed distribution 


\section{Results}

\section{CIRCULATORY VARIABLES AND PLASMA}

CATECHOLAMINES AT REST

Group $T$ had a higher thoracic impedance in comparison with group $\mathrm{C}$, indicating a smaller pulmonary blood volume in group $\mathrm{T}$ than in group $\mathrm{C}$ $(0.97 \pm 0.07 \Omega / \mathrm{cm}$ vs $0.87 \pm 0.08 \Omega / \mathrm{cm}, \mathrm{p}<0.01)$. Heart rates were similar in the two groups. The impedance methods provided indices of heart contractility. $\mathrm{dZ} / \mathrm{dt}$ max was $2 \cdot 40 \pm 0.36 \Omega / \mathrm{s}$ in group $T$ and $1.95 \pm 0.53 \Omega / \mathrm{s}$ in group $\mathrm{C}(\mathrm{p}<0.05)$ and $(\mathrm{dZ} / \mathrm{dt}) \times(\mathrm{R}-\mathrm{Z})^{-1}$ was $23.4 \pm 4.6 \Omega / \mathrm{s}$ and $18 \cdot 3 \pm 7 \cdot 3$ $\Omega / \mathrm{s}^{2}$, respectively $(\mathrm{p}<0.05)$. PEP was $0.104 \pm 0.008 \mathrm{~s}$ in group $T$ and $0 \cdot 105 \pm 0.010 \mathrm{~s}$ in group $\mathrm{C}$, and PEPc $0.107 \pm 0.010 \mathrm{~s}$ in both groups. LVET was $0.258 \pm 0.014 \mathrm{~s}$ in group $\mathrm{T}$ and $0.268 \pm 0.028 \mathrm{~s}$ in group C (NS) and LVETc was $0.267 \pm 0.013 \mathrm{~s}$ and $0.279 \pm 0.026 \mathrm{~s}$, respectively (NS). Systolic blood pressure was higher in group $\mathrm{T}$ than in group $\mathrm{C}$, whereas diastolic blood pressure was similar in the two groups at rest (Fig. 1 and Table 1).

Plasma noradrenaline but not adrenaline was increased in group $T$ at rest (Fig. 2, Table 1). No correlations were found in the two groups between plasma noradrenaline and PEP or systolic blood pressure at rest. There was a positive correlation between systolic blood pressure and plasma adrenaline in the control group $(\mathrm{r}=0.71, \mathrm{p}<0.01)$.

\section{MENTAL STRESS}

The self rated score of "stress" in daily living was higher in group $T$ than in group $C(p<0.01)$. The two groups performed equally well and the experience of stress induced by the colour word test was rated similar by the two groups. Heart rate and systolic blood pressure increased to a similar extent in both groups during the mental stress whereas diastolic blood pressure increased more in group $T$ than in group C (Fig. 1, Table 1). Both plasma adrenaline and noradrenaline increased in the two groups with a higher absolute and percentage increase of plasma adrenaline in group $\mathrm{T}$ (Fig. 2, Table 1).

\section{SUSTAINED ISOMETRIC HAND GRIP TEST}

The heart rate increased significantly and to the same extent in the two groups (Table 2). The increase in systolic blood pressure was similar in the two groups during the test, the increase being maintained in group $\mathrm{T}$ (Fig. 1, Table 2). There were more rapid increases in diastolic blood pressure in group $T$ during isometric exercise (Fig. 1). Plasma

Table 2 Heart rate $(H R)$, blood pressures (SBP, DBP), and plasma catecholamines with isometric hand grip test, cold pressor test, and after intravenous administration of atropine in subjects with $T$ wave abnormalities and normal electrocardiograms (group $C$ )

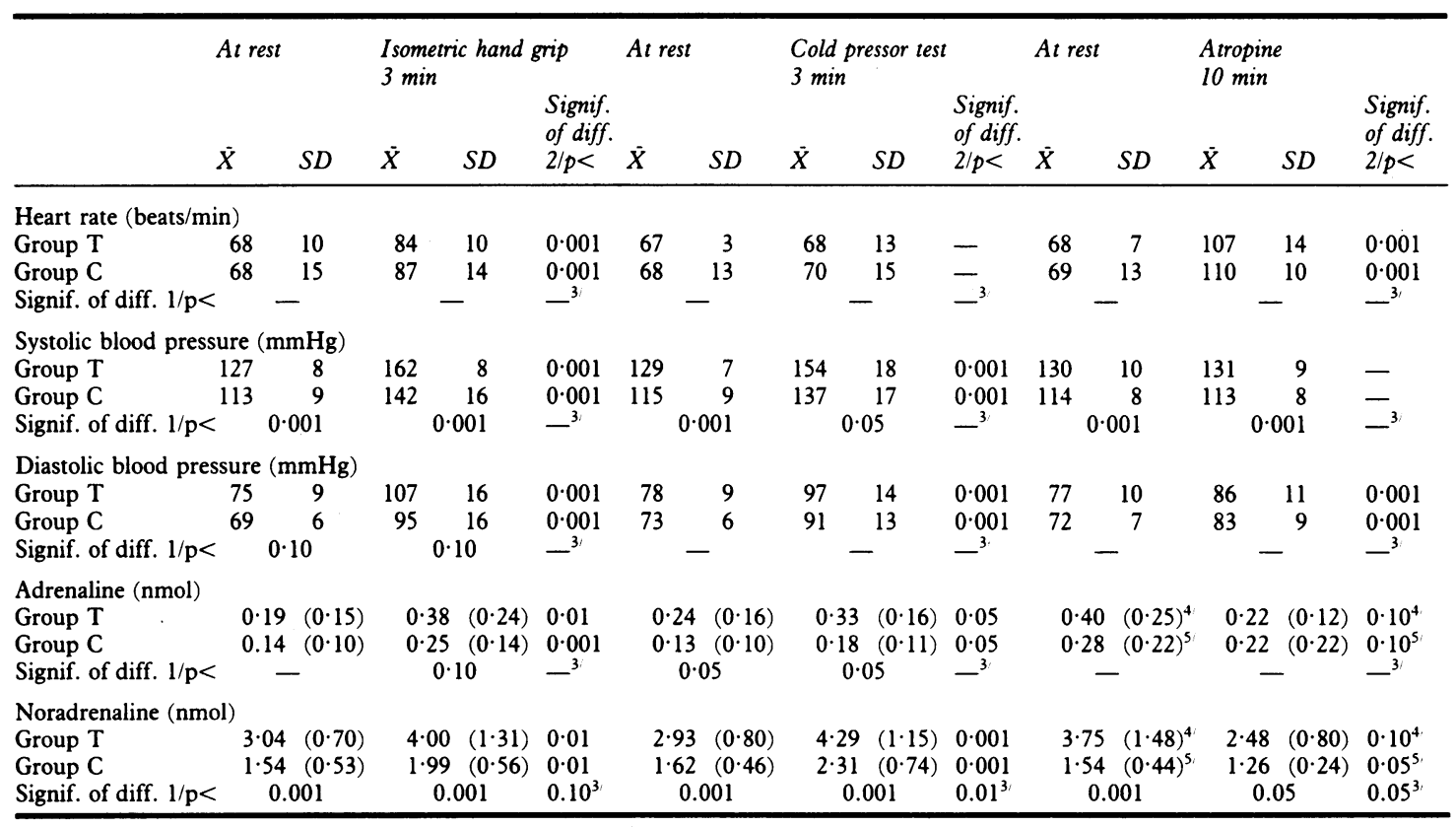

Statistical comparisons as in Table $1.4 / n=4,5 / n=7$. 
noradrenaline and adrenaline increased similarly and significantly in the two groups (Fig. 3, Table 2).

COLD PRESSOR TEST

The heart rate did not change in either group whereas both systolic and diastolic blood pressure increased to the same extent in the two groups (Fig. 1, Table 2). Plasma noradrenaline and adrenaline were increased by the cold pressor test in both groups. The increase in noradrenaline was significantly more pronounced in group $\mathrm{T}$ (Fig. 2, Table 2).

\section{EFFECTS OF ATROPINE}

After atropine (mean doses of $1.27 \mathrm{mg}$ in group $\mathrm{T}$ and $1.35 \mathrm{mg}$ in group $\mathrm{C}$ ) there was a similar increase in heart rate in the two groups (Table 2). No change in systolic blood pressure was observed in either group whereas diastolic blood pressure showed an increase
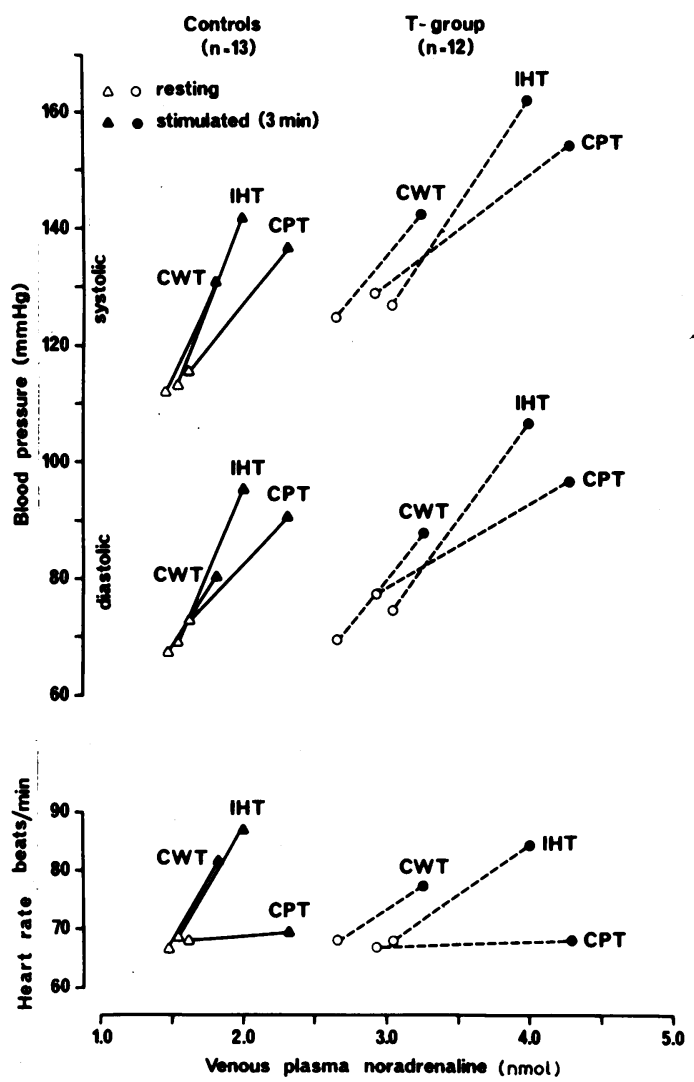

Fig. 3 A schematic representation (mean values) of the relations between plasma noradrenaline and heart rate, systolic and diastolic blood pressures before and after three minutes of mental stress $(C W T)$, isometric hand grip $(H T)$, and cold pressor test (CPT) in subjects with $T$ wave abnormalities (interrupted lines) and normal electrocardiograms (continuous lines). that was similar in the two groups (Table 2). Both plasma adrenaline and noradrenaline decreased after atropine (Table 2).

\section{CHANGES IN IMPEDANCE VARIABLES DURING}

PROVOCATIONS

PEP and PEPc decreased during the initial part of the mental stress test in both groups but remained lower somewhat longer in group $T(p<0.01)$. During isometric exercise PEP and PEPc were shortened in group $T(p<0.01$ and $<0.05$, respectively) but not in group $C$. No significant change was observed in PEP or PEPc in either group during the cold pressor test. After atropine, PEP and PEPc increased in group C $(p<0.01$ and $p<0.001$, respectively) but not in group T. LVET and LVETc were significantly shortened during the whole mental stress test in group $\mathrm{C}$ but only during the last minutes in group T. LVET and LVETc also decreased significantly during the isometric hand grip test in the control group. No changes were seen during the cold pressor test in either group. Both groups had shorter LVET and LVETc after atropine and there were no differences between the two groups.

$\mathrm{Z}_{0}$ and the contractility indices $\mathrm{dZ} / \mathrm{dt} \max$ and $\mathrm{dZ} / \mathrm{dt} \max \times(\mathrm{R}-\mathrm{Z})^{-1}$ were significantly higher in group $T$ during all examinations. $Z_{0}$ had increased by an average of $0.017 \Omega / \mathrm{cm}$ in group $C$ at the end of the experiment but before atropine, as compared with the initial measurements $(p<0.001)$. There was no similar, significant change in group $T$ during the experiment, indicating that thoracic blood volumes decreased more in group $\mathrm{C}$ than in group $\mathrm{T}$ during the course of the experiment.

\section{PLASMA DOPAMINE}

Resting unconjugated plasma dopamine levels were $0 \cdot 15 \pm 0 \cdot 10 \mathrm{nmol}$ in group $\mathrm{C}$ and $0 \cdot 12 \pm 0.09 \mathrm{nmol}$ in group $\mathrm{T}$ (not significantly different). No significant changes in these levels were found in either group in connection with the stress tests or the administration of atropine.

INTERRELATIONS BETWEEN HAEMODYNAMIC AND CATECHOLAMINE VARIABLES IN RESPONSE TO STRESS

The relation between changes in blood pressure and changes in heart rate, adrenaline, or noradrenaline was different in the three stress tests (Fig. 3, Table 3). Mental stress provoked increases in blood pressure, which were significantly related to increases in heart rate. Cold induced changes in blood pressure were related to noradrenaline. During isometric exercise the blood pressure and pulse rate both increased with the rise in adrenaline and noradrenaline. In general, the ratio of blood pressure to noradrenaline increase 
was smaller during the cold pressor test than during the colour word test or the isometric hand grip tests in both groups (Fig. 3). In both groups heart rate rose with the increased adrenaline levels during the mental stress test and with adrenaline levels and noradrenaline during isometric exercise (Table 3).

Changes in PEP in group $\mathrm{T}$ were negatively related to changes in heart rate during the colour word test $(p<0 \cdot 10)$ and the isometric hand grip test $(p<0.01)$ and to changes in noradrenaline during the isometric hand grip test $(p<0.01)$. A negative correlation was found between PEP and noradrenaline in group $C$ during mental stress $(p<0.01)$.

\section{Discussion}

The present study provides evidence in favour of increased sympathetic activity as a cause of primary $T$ wave abnormalities in the electrocardiogram. Thus, we found that plasma noradrenaline, a good indicator of sympathetic nerve activity, ${ }^{12-14}$ was nearly doubled in our group $\mathrm{T}$ at rest. This highly significant increase in plasma noradrenaline was seen both at rest and in connection with stressful provocations causing different patterns of haemodynamic responses. Similarly, Atterhög and Ekelund have shown that a corresponding group of men had shortened systolic time intervals, indicating increased cardiac sympathetic tone; the $\mathrm{T}$ wave abnormalities found were counteracted by beta-adrenoceptor blockade. ${ }^{15}$ Heart rates in group $T$ were similar to those in group $\mathrm{C}$, both at rest and during provocation, despite signs of increased sympathetic activity and cardiac contractility (as measured by the indices $\mathrm{dZ} / \mathrm{dt}$ and $\mathrm{dZ} / \mathrm{dt} \times(\mathrm{R}-\mathrm{Z})^{-1}$ on impedance cardiography). This might be the result of a simultaneous rise in opposing vagal activity in group $T$. We find it difficult to interpret our results regarding heart rate after atropine because we do not know how complete the cholinergic blockade was, and there was a simultaneous decrease in plasma noradrenaline indicating reduced sympathetic tone. Atropine was therefore not useful in assessing the importance of vagal activity for the heart rates in our subjects.

All three stress tests used in the present studymental stress, isometric hand grip, and cold pressor test-caused significant increases in plasma noradrenaline, indicating sympathetic activation. The size of the noradrenaline response was similar to that reported by workers using radio-enzymatic methods, with regard to the effects of isometric hand grip ${ }^{16-18}$ and cold provocation. ${ }^{1618}$ Robertson and coworkers, ${ }^{18}$ like us, also found rises in circulating adrenaline in connection with isometric exercise and cold. Even though effects of mental stress are considered to be mediated by adrenaline (c.f. ${ }^{19}$ ) very few data appear to exist regarding plasma catecholamines during mental stress. Stressful arithmetic has been shown to increase "total" catecholamines in plasma ${ }^{20}$ and circulating adrenaline. ${ }^{21}$ The standardised mental stress used in the present study, a modified version of Stroop's colour word conflict test, increases adrenaline excretion in the urine. ${ }^{7}$ The present results show only minor increases in plasma adrenaline during mental stress, especially in the healthy controls. Thus, the effects of mental stress seem to be mediated by neurogenic mechanisms rather than by circulating adrenaline as discussed previously by us. ${ }^{22}$

Apart from increases in blood pressure, the

Table 3 Significance of stress induced changes in systolic and diastolic blood pressure and heart rate as related to changes in heart rate, adrenaline, and noradrenaline

\begin{tabular}{|c|c|c|c|c|c|c|}
\hline & \multicolumn{3}{|l|}{ Group $T$} & \multicolumn{3}{|l|}{ Group C } \\
\hline & $\begin{array}{l}\text { Heart rate } \\
p<\end{array}$ & $\begin{array}{l}\text { Adrenaline } \\
p<\end{array}$ & $\begin{array}{l}\text { Noradrenaline } \\
p<\end{array}$ & $\begin{array}{l}\text { Heart rate } \\
p<\end{array}$ & $\begin{array}{l}\text { Adrenaline } \\
p<\end{array}$ & $\begin{array}{l}\text { Noradrenaline } \\
p<\end{array}$ \\
\hline \multicolumn{7}{|c|}{ Systolic blood pressure } \\
\hline CWT & 0.01 & - & - & 0.01 & 0.05 & $0 \cdot 10$ \\
\hline IHT & 0.01 & 0.05 & $0 \cdot 10$ & 0.05 & 0.01 & 0.05 \\
\hline $\mathrm{CPT}$ & - & - & 0.01 & - & 0.05 & 0.01 \\
\hline \multicolumn{7}{|c|}{ Diastolic blood pressure } \\
\hline CWT & 0.01 & 0.05 & - & 0.01 & 0.05 & $0 \cdot 10$ \\
\hline IHT & 0.01 & 0.05 & $0 \cdot 10$ & 0.05 & 0.01 . & 0.05 \\
\hline $\mathrm{CPT}$ & - & - & 0.01 & - & 0.05 & 0.01 \\
\hline \multicolumn{7}{|c|}{ Heart rate } \\
\hline CWT & - & $0 \cdot 10$ & - & - & 0.05 & - \\
\hline IHT & - & 0.05 & $0 \cdot 10$ & - & 0.01 & 0.05 \\
\hline CPT & - & - & - & - & - & - \\
\hline
\end{tabular}

The p values were obtained by applying the sign test to the individual slopes in the two groups, respectively; CWT, colour word test; IHT, isometric hand grip test; and CPT, cold pressor test. 
haemodynamic responses to the stress tests used in the present investigation included increases in heart rate and, in the T group, reductions in PEP and PEPc in connection with mental stress and isometric hand grip. The cold pressor test, on the other hand, did not influence either heart rate or PEP. These results support the finding that blood pressure is raised mainly by cardiac stimulation in connection with mental stress (e.g. ${ }^{23-25}$ ) and isometric exercise (e.g. ${ }^{26-30}$, whereas peripheral vasoconstriction accounts for the blood pressure response to cold provocation. ${ }^{23} 2930$ The relations illustrated in Fig. 3 between increases in plasma noradrenaline and effects of these tests on blood pressure and heart rate may also be interpreted along these lines. Thus, tests causing more or less selective activation of the heart (viz. mental stress and isometric exercise) would raise blood pressure more in relation to a given increase in plasma noradrenaline than a test (such as a cold pressor test) causing generalised vasoconstriction, thereby activating a greater number of the sympathetic neurons.

The rise in plasma noradrenaline in group $T$ was accompanied by an increase in systolic blood pressure throughout the series of tests. We could not show significant interindividual correlations between blood pressure and noradrenaline at rest within either group $\mathrm{T}$ or group C. Correlations were found, however, between blood pressure responses to stress and noradrenaline. Other clinical data indicate a relation between blood pressure and sympathetic activity. ${ }^{31} 32$ Similarly, experiments with pithed rats show excellent agreement between increments in blood pressure and noradrenaline levels in plasma. ${ }^{14}$ It is therefore likely that the higher levels of systolic blood pressure found in group $T$ were, at least in part, caused by the clear-cut increase in sympathetic activity.

The present investigation shows not only an increased level of sympathetic activity in group $\mathrm{T}$ at rest, but also signs of increased reactivity in these subjects in response to stress. Plasma noradrenaline increased more in group $T$ than in group $C$ in connection with each of the stress tests used, though the percentage increase in both groups was similar, because of higher resting levels in group $T$. Adrenaline and diastolic blood pressure increased more in group $\mathrm{T}$ than in group $\mathrm{C}$ during mental stress and isometric hand grip. Similarly, group $T$ showed a tendency towards larger reductions in PEP and PEPc during these tests, indicating greater increases in cardiac contractility. Thus, evidence in favour of increased sympathoadrenal reactivity was found in these young men with $T$ wave abnormalities in the electrocardiogram.

In conclusion, the present study strongly suggests that asymptomatic young men with primary $\mathrm{T}$ wave abnormalities in the electrocardiogram have increased sympathetic tone at rest and a tendency towards increased sympathoadrenal reactivity in connection with various kinds of stress. This increase in sympathoadrenal activity is accompanied by signs of increased cardiac contractility and a rise in systolic blood pressure. It appears that the electrocardiographic abnormalities in these men may be caused by a high level of sympathetic activity.

\section{References}

1 Blom G. A review of electrocardiographic changes in emotional states. $\mathcal{F}$ Nerv Ment Dis 1951; 113: 283-300.

2 Taggart P, Carruthers M, Somerville W. Emotions, catecholamines and the electrocardiogram. In: Yu PN, Goodwin JF, eds. Progress in cardiology. 7. Philadelphia: Lea \& Febiger, 1978: 103-24.

3 Furberg C. Adrenergic beta-blockade and electrocardiographical ST-T-changes. Acta Med Scand 1967; 181: 21-32.

4 Taggart P, Carruthers M, Joseph S, et al. Electrocardiographic changes resembling myocardial ischaemia in asymptomatic men with normal coronary arteriograms. Br Heart f 1979; 41: 214-25.

5 Guazzi M, Fiorentini C, Polese A, Magrini F, Olivari MT. Stress-induced and sympathetically mediated electrocardiographic and circulatory variations in the primary hyperkinetic heart syndrome. Cardiovasc Res 1975; 9: 342-54.

6 Atterhög J-H, Eliasson K, Hjemdahl P. Electrocardiographic and vectorcardiographic findings in young asymptomatic men with primary $\mathrm{T}$ wave aberrations in the electrocardiogram. Relationship to sympatho-adrenal activity at rest and during different stress tests. Submitted for publication.

7 Frankenhaeuser M, Mellis I, Rissler A, Björkvall C, Patkai P. Catecholamine excretion as related to cognitive and emotional reaction patterns. Psychosom Med 1968; 30: $109-24$.

8 Johansson G. Subjective wellbeing and temporal patterns of sympathetic-adrenal medullary activity. Biol Psychol 1976; 4: 157-72.

9 Hjemdahl P, Daleskog M, Kahan T. Determination of plasma catecholamines by high performance liquid chromatography with electrochemical detection: comparison with a radioenzymatic method. Life Sci 1979; 25: 131-8.

10 Gabriel S, Atterhög J-H, Orö L, Ekelund L-G. Measurement of cardiac output by impedance cardiography in patients with myocardial infarction. Comparative evaluation of impedance and dye dilution methods. Scand 7 Clin Lab Invest 1976; 36: 29-34.

11 Weissler AM, Harris WS, Schoenfeld CD. Systolic time intervals in heart failure in man. Circulation 1968; 37: 149-59.

12 Cryer PE. Isotope-derivative measurements of plasma norepinephrine and epinephrine in man. Diabetes 1976; 25: $1071-82$. 
13 Kopin IJ. Biochemical assessment of peripheral adrenergic activity. In: Paton DM, ed. The release of catecholamines from adrenergic neurons. Oxford: Pergamon Press, 1979: 355-72.

14 Yamaguchi I, Kopin IJ. Plasma catecholamine and blood pressure responses to sympathetic stimulation in pithed rats. Am $\mathcal{F}$ Physiol 1979; 237: H305-H310.

15 Atterhög J-H, Ekelund L-G. Significance of primary T wave aberrations in the electrocardiogram of asymptomatic young men. Part III. Systolic time intervals and autonomic tone. Scand $\mathcal{F}$ Clin Lab Invest 1980; accepted for publication.

16 Lake CR, Ziegler MG, Kopin IJ. Use of plasma norepinephrine for evaluation of sympathetic neuronal function in man. Life Sci 1976; 18: 1315-25.

17 Vecht RJ, Graham GWS, Sever PS. Plasma noradrenaline concentrations during isometric exercise. Br Heart F 1978; 40: 1216-20.

18 Robertson D, Johnson GA, Robertson RM, Nies AS, Shand DG, Oates JA. Comparative assessment of stimuli that release neuronal and adrenomedullary catecholamines in man. Circulation 1979; 59: 637-43.

19 Frankenhaeuser M. Behaviour and circulating catecholamines. Brain Res 1971; 31: 241-62.

20 Falkner B, Onesti G, Angelakos ET, Fernandes $M$, Langman C. Cardiovascular response to mental stress in normal adolescents with hypertensive parents. Hypertension 1979; 1: 23-30.

21 Bonelli J, Hörtnagl H, Brücke T, Magometschnigg D, Lochs H, Kaik G. Effect of calculation stress on haemodynamics and plasma catecholamines before and after $\beta$-blockade with propranolol $\left(\right.$ Inderal $^{\mathbf{R}}$ ) and mepindolol sulfate $\left(\right.$ Corindolan $\left.^{R}\right)$. Eur $\mathcal{F}$ Clin Pharmacol 1979; 15: 1-8.

22 Hjemdahl P, Eliasson K. Sympatho-adrenal and cardiovascular response to mental stress and orthostatic provocation in latent hypertension. Clin Sci 1979; 57: 189s-91s.
23 Brod J. Haemodynamic basis of acute pressor reactions and hypertension. Br Heart $\mathcal{F}$ 1963; 25: 227-45.

24 Guazzi M, Magrini F, Olivari MT, Polese A, Fiorentini C. Influences of the adrenergic nervous system on the repolarization phase of the electrocardiogram. Angiology 1978; 29: 617-30.

25 Ulrych $M$. Changes of general haemodynamics during stressful mental arithmetic and non-stressing quiet conversation and modification of the latter by betaadrenergic blockade. Clin Sci 1969; 36: 453-61.

26 Mitchell JH, Wildenthal K. Static (isometric) exercise and the heart. Ann Rev Med 1974; 25: 369-81.

27 Hoel BL, Lorentsen E, Lund-Larsen PG. Haemodymaic responses to sustained hand-grip in patients with hypertension. Acta Med Scand 1970; 188: 491-5.

28 Helfant RH, de Villa MA, Meister SG. Effect of sustained isometric hand grip exercise on left ventricular performance. Circulation 1971; 44: 982-93.

29 Hines EA, Jr, Brown GE. The cold pressor test for measuring the reactibility of the blood pressure: data concerning 571 normal and hypertensive subjects. Am Heart f 1936; 11: 1-9.

30 Cuddy RP, Smulyan H, Keighley JF, Markason CR, Eich RH. Haemodynamic and catecholamine changes during a standard cold pressor test. Am Heart 7 1966; 71 : 446-54.

31 Louis WJ, Jarrott B, Doyle AE. The role of the autonomic nervous system in human hypertension: studies in essential hypertension and in phaeochromocytoma. In: Berglund G, Hansson L, Werkö L, eds. Pathophysiology and management of arterial hypertension. Mölndal, Sweden: Lindgren \& Söner AB, 1975: 16-21.

32 de Champlain J. The sympathetic system in hypertension. Clin Endocrinol Metab 1977; 6: 633-55.

Requests for reprints to Dr J-H Atterhög, Department of Clinical Physiology, Karolinska Sjukhuset, S-104 01 Stockholm, Sweden. 